\title{
Os Egressos de Pós-Graduação em Saúde Coletiva: Construindo um Perfil
}

\author{
Paulete Goldenberg ${ }^{1}$ \\ Simone Schenkman ${ }^{1}$
}

\begin{abstract}
Resumo: Este artigo tem por objetivo construir o perfil dos egressos de Pós-Graduação em Saúde Coletiva, tendo como eixos principais a inserção no mercado de trabalho, a divulgação da produção científica referente à defesa de tese e a relevância da Pós-Graduação. A ABRASCO encaminhou um formulário (a ficha $C$ ) para as coordenações dos cursos de Pós-Graduação, que se encarregariam de seu preenchimento junto aos egressos. Obtivemos respostas de $51,5 \%$ do universo de egressos que concluíram o mestrado ou doutorado entre 1990-94 ( $\mathrm{N}=257$ ). Os egressos, em sua maioria, estavam inseridos no mercado de trabalho na qualidade de docentes e pesquisadores em universidades, instituições e fundações públicas, chamando a atenção a presença significativa de egressos inseridos nos serviços público-assistenciais de saúde, bem como exercendo funções administrativas. Quando indagados sobre a relevância da PósGraduação em suas vidas profissionais, a maioria se reportou a alterações de atividades e aumento de salário. A elevada proporção de divulgação das dissertações/teses, e seu crescente aumento nos anos estudados, apontaram para a aproximação do desempenho da área de Saúde Coletiva em relação às demais áreas de Pós-Graduação.
\end{abstract}

Palavras-chave: Avaliação; Egressos; Pós-Graduação; Saúde Coletiva.

Summary: The aim of this paper is to draw a profile of Public Health postgraduates, through the evaluation of their jobs, scientific production and the relevance of the degree to their career. An instrument (called "C form") was sent by ABRASCO to all institutions in Brazil that offer Public Health postgraduate courses. $51,5 \%$ of the universe of postgraduate students with a Master or Doctor degree, obtained throughout the years of 1990-94, answered the questionnaire. Most of the postgraduates were involved in teaching or research; however, a significant proportion was also working in health services or administrative assignments. When inquired about the relevance of the degree to their career, most postgraduates described changes in their activities or better wages. The efficient diffusion of the findings of their dissertations, as well as the increasing strength of this process of diffusion in recent years corroborate the evidence that the profile of the Public Health postgraduation courses is becoming similar to other postgraduation courses in Brazil, most of them with good standards of quality.

Keywords: Evaluation process; Postgraduates students; Postgraduation courses; Public Health.

1 Departamento de Medicina Preventiva da Escola Paulista de Medicina / UNIFESP 


\section{Apresentação}

O presente levantamento tem por objetivo responder à questão: onde estão os pósgraduandos em Saúde Coletiva, que defenderam dissertação/tese de mestrado ou doutorado no período de 1990 a 1994? O que produziram em termos de divulgação das dissertações/teses defendidas? Qual o significado da Pós-Graduação para sua vida profissional?

Estas questões deveriam ser respondidas pelo componente de Egressos, que integrava, originalmente, um projeto mais amplo promovido e coordenado pela Associação Brasileira de Pós-Graduação em Saúde Coletiva ABRASCO (Minayo \& Costa, 1994), com o propósito de proceder a uma avaliação da área de Pós-Graduação em Saúde Coletiva. Em meio às tramitações para obtenção de financiamento, e atendendo à solicitação de preparação de um diagnóstico com vistas à avaliação externa a ser realizada pela Fundação Coordenação de Aperfeiçoamento de Pessoal de Nível Superior - CAPES, o levantamento foi redimensionado. Previsto para ser realizado em um prazo excessivamente curto, a investigação em torno dos egressos destes programas reduziu-se a uma sondagem. Se de um lado ela ofereceu a oportunidade de um contato preliminar com o tratamento das referidas questões, tendo em vista o desenvolvimento do projeto, em fase de planejamento, esta sondagem também traz, por outro lado, as marcas das limitações de uma abordagem sucinta de um complexo tema de investigação.

O processo avaliativo desencadeado pela ABRASCO, articulado em paralelo ao EXECAPES, tinha como proposta subsidiar a reflexão sobre a inserção da referida área no campo mais geral da Ciência \& Tecnologia, e aperfeiçoar mecanismos de avaliação sintonizados e validados de acordo com as dinâmicas internacionais de formação profissional e aperfeiçoamento de indicadores de avaliação (Minayo \& Costa, 1996). Referenciada à especificidade da área, bem como à aproximação com o desenvolvimento de outras áreas, a investigação propunha discutir a universalidade de critérios de avaliação dos cursos de Pós-Graduação, ao lado da caracterização do perfil da clientela e da revisão de cursos com vistas a adequar a formação de profissionais às necessidades da área de Saúde Coletiva.

Diante da impossibilidade de trabalhar a trajetória de especialização a par da profissionalização dos ex-alunos (egressos) da PósGraduação em Saúde Coletiva, conforme previa o sub-projeto de egressos (Goldenberg et al., 1994), a presente sondagem acabou por se restringir à coleta de informações sobre a inserção atual dos egressos no mercado de trabalho e o exercício de atividades complementares, além de informações relacionadas à qualificação profissional e à identificação sucinta da divulgação das dissertações ou teses no âmbito da produção técnico-científica, seguidas da indagação sobre a relevância da pós-graduação na vida profissional dos egressos.

No caso da inserção no mercado de trabalho, tratava-se de identificar, ao lado da tradicional clientela acadêmica, a presença de alunos oriundos da área de serviços assistenciais, que vinha sendo apontada como um traço novo do perfil dos alunos incorporados nesta área na Pós-Graduação (Minayo \& Costa, 1994).

Institucionalizada nos anos 60, a PósGraduação visava a formação de docentes e pesquisadores. A Reforma Universitária ratifiCa a instalação da Pós-Graduação estabelecendo, a partir daí, políticas de expansão de cursos, na esteira dos quais emergem, na década de 70, os primeiros cursos de PósGraduação stricto sensu na área de Saúde Coletiva. As pressões que se instauram para titulação, apoiadas na atuação das agências financiadoras, particularmente no âmbito de estabelecimentos públicos de ensino e pesquisa, acabariam demarcando o espaço de 
inserção dos egressos da área no mercado de trabalho.

A expansão desordenada do ensino superior nos anos subseqüentes, por sua vez, levantaria a questão da qualidade dos cursos de Pós-Graduação e a necessidade de sua avaliação, enfatizando, desde logo, a preocupação com a produtividade, ressaltando as dificuldades de implementação das atividades de pesquisa nos cursos de Pós-Graduação (Madeira, 1996).

De acordo com Durham (1989) e Schwartzman (1989), na medida em que o ensino universitário em geral se torna mais complexo, seja pela incorporação das atividades de pesquisa seja pela sua própria expansão, ampliando o universo de vagas, a questão do aumento dos custos ganha destaque em meio à crise fiscal dos governos federais e estaduais. Ao lado da preocupação com a produção do conhecimento, o mercado de trabalho se diversifica, ampliando a gama de serviços que a sociedade tende a exigir, questionando-se a capacidade da Universidade de qualificar profissionalmente os alunos para atuar no mercado de trabalho.

Nos anos 80, consolida-se a avaliação institucional do ensino superior. Enquanto recurso de tomada de decisões e gerenciamento, a proposta da avaliação é apresentada como instrumento de racionalização de gastos e canalização de financiamento em geral, referenciada à questão da autonomia universitária, que ganha destaque renovado. Tendo por pano de fundo o processo de redemocratização em curso, o governo preconiza a avaliação sistemática, utilizando como argumento a necessidade de estabelecer padrões de qualidade que atendessem à exigência de visibilidade social da Universidade (MEC-SES, 1988).

Em meio à polêmica que estas proposições e sua instrumentalização suscitam, consolida-se o espectro da avaliação, sendo reforçada a utilização de indicadores de desempenho científico (Amorim, 1992), extensi- vos à área de Saúde Coletiva, em que pese a alegada especificidade de sua constituição.

Nestas circunstâncias explicita-se a crítica à universalidade da aplicação dos critérios adotados (valorizando a quantidade de publicações e em determinados veículos) na avaliação da área, invocando-se a especificidade da expressão de sua produção científica (Minayo \& Costa, 1994). Diante destas indagações, resguardados os limites da presente sondagem, a apuração de dados buscou identificar o volume de divulgação das dissertações/teses por veículos utilizados, suspeitando-se ainda que o volume de difusão seria maior quanto maior fosse o tempo transcorrido descle a defesa de dissertação/ tese, tendo em vista as dificuldades envolvidas em sua execução.

Quanto à relevância da Pós-Graduação no processo de qualificação profissional, diante da complexidade que a abordagem desta questão requer, limitamo-nos a indagar, de forma sucinta, a sua relação com alteração de atividades desempenhadas e aumento de salário, deixando em aberto a possibilidade de identificar pistas que subsidiariam a abordagem do problema em investigações futuras.

\section{Procedimentos de Investigação}

Diante do processo de redução do projeto original, foi elaborada a ficha $C$ (em ane$\mathrm{xo}$ ), atendendo às necessidades estabelecidas para o levantamento de informações do componente de egressos. A ABRASCO se encarregou de encaminhar formulário cujo preenchimento ficaria sob responsabilidade das coordenações das pós-graduações da Escola Nacional de Saúde Pública (ENSP), Faculdade de Medicina de Ribeirão Preto da USP (FMRP-USP), Faculdade de Saúde Pública da USP (FSP-USP), Medicina Preventiva da USP (MP-USP), Universidade Estadual de Londrina (UEL), Universidade Estadual do Rio de 


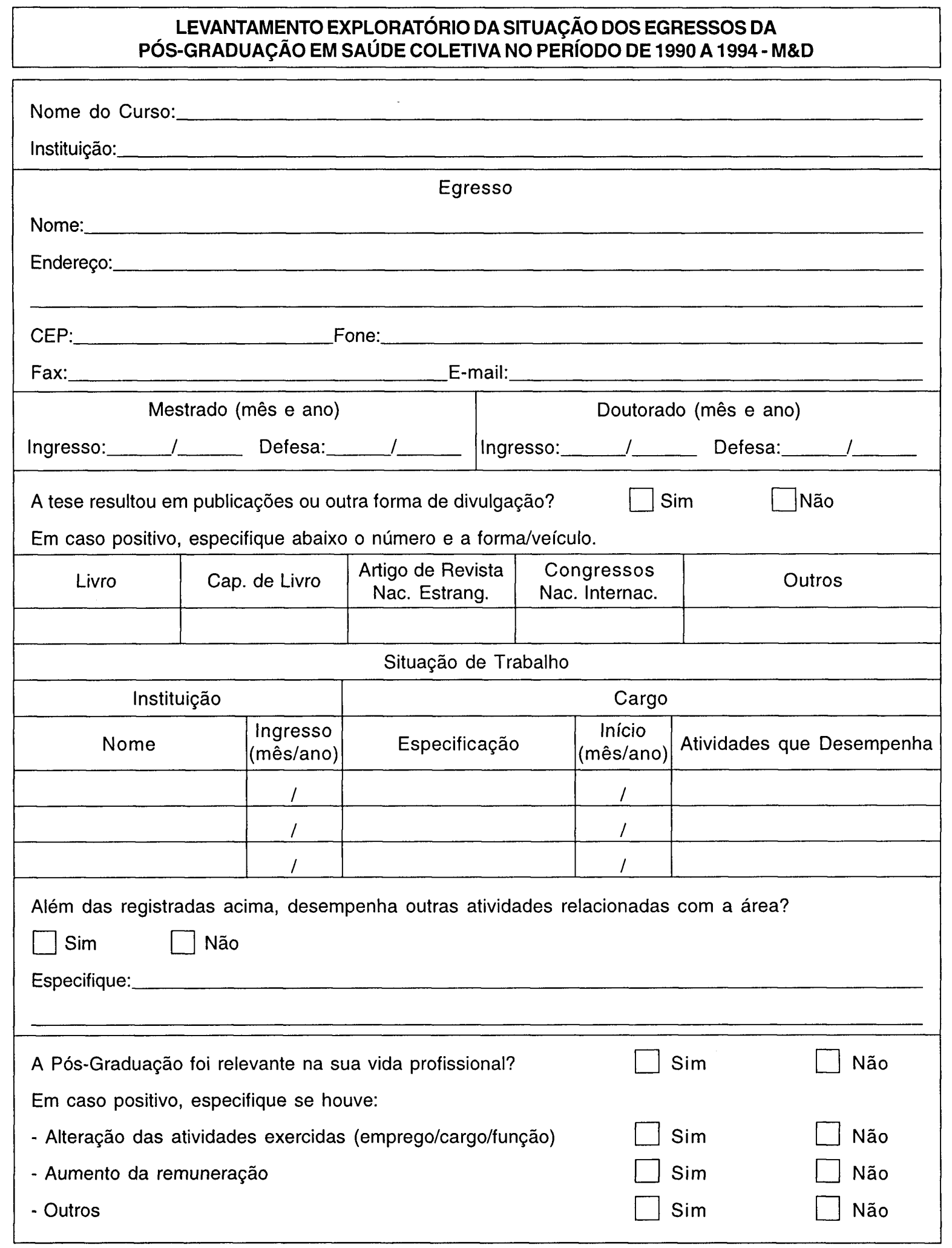


Janeiro (UERJ), Universidade Federal da Bahia (UFBa), Universidade Federal de Pelotas (UFPel), Universidade de Campinas (UNICAMP) e Universidade Federal de São Paulo (UNIFESP/EPM).

Vislumbrando identificar, inicialmente, a proporção de ex-alunos localizados ou acessados, recorremos à coordenação destas instituições para obtermos tais informações, bem como para esclarecer outras. Nas instituições com maior número de pós-graduandos, foi menor o acesso aos egressos (Tabela 1), como seria de se esperar. Os níveis mais baixos de acesso foram observados na FSP-USP $(27,8 \%)$, seguidos da UERJ, com 46,2\%. do estudado, registramos a data da defesa de tese do nível mais recente. Dado que o número de doutorandos era muito pequeno, descartamos para efeito de apresentação dos resultados a estratificação por nível de titulação.

Vale dizer a respeito do preenchimento de dados, da dificuldade de acessar egressos fora do espaço da instituição de Pós-Graduação, resultando a suspeita de ter havido concentração de informes sobre egressos que se encontravam nas respectivas instituições, na qualidade de funcionários ou alunos (de doutorado), tanto em escolas mais antigas e de maior porte (UERJ e FSP-USP), como em pós-graduações mais recentes (UNIFESP-EPM).

Tabela 1

Informes (ficha $C$ ) sobre Egressos de Mestrado e Doutorado em Saúde Coletiva, segundo Instituição, no Período de 1990 a 1994

\begin{tabular}{|c|c|c|c|c|c|c|c|c|c|}
\hline \multirow{3}{*}{ Instituição } & \multicolumn{3}{|c|}{ Mestrado } & \multicolumn{3}{|c|}{ Doutorado } & \multicolumn{3}{|c|}{ Mestrado + Doutorado } \\
\hline & \multirow{2}{*}{$\begin{array}{l}\text { Total de } \\
\text { Egressos }\end{array}$} & \multicolumn{2}{|c|}{ Enviadas } & \multirow{2}{*}{$\begin{array}{l}\text { Total de } \\
\text { Egressos }\end{array}$} & \multicolumn{2}{|c|}{ Enviadas } & \multirow{2}{*}{$\begin{array}{l}\text { Total de } \\
\text { Egressos }\end{array}$} & \multicolumn{2}{|c|}{ Enviadas } \\
\hline & & № & $\%$ & & № & $\%$ & & № & $\%$ \\
\hline ENSP & 134 & 88 & 65,7 & 12 & 6 & 50,0 & 146 & 94 & 64,4 \\
\hline FMRPNSP & 15 & 15 & 100,0 & 7 & 7 & 100,0 & 22 & 22 & 100,0 \\
\hline FSPNSP & 115 & 37 & 32,2 & 72 & 15 & 20,8 & 187 & 52 & 27,8 \\
\hline MPNSP & 19 & 15 & 78,9 & 7 & 7 & 100,0 & 26 & 22 & 84,6 \\
\hline UEL & 2 & 2 & 100,0 & 0 & 0 & - & 2 & 2 & 100,0 \\
\hline UERJ & 63 & 28 & 44,4 & 2 & 2 & 100,0 & 65 & 30 & 46,2 \\
\hline UFBa & 33 & 20 & 60,6 & 0 & 0 & - & 33 & 20 & 60,6 \\
\hline UFPel & 8 & 5 & 62,5 & 0 & 0 & - & 8 & 5 & 62,5 \\
\hline UNICAMP & 1 & 1 & 100,0 & 1 & 1 & 100,0 & 2 & 2 & 100,0 \\
\hline UNIFESP/EPM & 8 & 8 & 100,0 & 0 & 0 & - & 8 & 8 & 100,0 \\
\hline Total & 398 & 219 & 55,0 & 101 & 38 & 37,6 & 499 & 257 & 51,5 \\
\hline
\end{tabular}

Do universo de egressos que concluíram o mestrado ou doutorado entre 1990 e 1994, foram acessados 51,5\%. Algumas instituições enviaram informes de egressos que defenderam tese após 1994. Estes dados foram registrados contando com a expansão do trabalho, porém não foram considerados para efeito do presente artigo.

Nos raros casos em que a defesa das teses de mestrado e doutorado ocorreram no perío-
Em se tratando de um estudo exploratório, aceitamos informações sobre quaisquer itens da ficha $C$, independentemente do preenchimento dos demais, desde que tivesse sido registrada a data da defesa de dissertação/tese. A propósito, na ausência de dados sobre o mês, adotamos convencionalmente o mês de janeiro para o início da Pós-Graduação, e dezembro para seu término. 
No item "divulgação das teses", levamos em consideração a existência de publicações e apresentação de trabalhos em congressos, registrando-se os demais canais de divulgaçào na categoria "outros". Diante do preenchimento não sistemático por parte de algumas instituições, o número de trabalhos produzidos ou apresentados não foi computado, ressaltando-se no tratamento das especificações da alternativa "outro" (veículo) a diversidade de especificações. Levantamos, por fim, a necessidade destes resultados serem estratificados por ano de defesa de dissertação/tese, atendendo à aposta de que a divulgação estaria relacionada com o tempo decorrido após a titulação.

A propósito, cabe ressaltar que os dados de divulgação foram apresentados nas tabelas por instituição de ensino, tendo em vista o retorno dos dados enviados, ainda que existam claras limitações com relação à análise neste nível de detalhamento.

A localização profissional, por referência ao momento da coleta de informações, envolveu a caracterização da inserção do egresso no mercado de trabalho em função do tipo e natureza da instituição, cargo e atividades. Paralelamente à média de empregos, foram priorizadas as situações de trabalho, levando em conta o fato de muitos dos egressos terem mais de um emprego.

No caso do tipo e natureza das instituições, foram consideradas, na codificação, as universidades, fundações e institutos, serviços de saúde e outros órgãos governamentais, bem como assistência em empresas, sempre por referência ao caráter público ou privado destas organizações. Considerando a categoria de autônomos, incluímos, por referência à natureza da instituição, o exercício das funções profissionais em consultórios privados, clínicas etc. Na categoria de instituições da sociedade civil, foram incluídas as ONGs, Conselhos, Sociedades, Associações, Sindicatos etc. Entre os casos sem informação foram incluídos os alunos, os aposenta- dos/afastados e dois casos que referiram não trabalhar, sendo esta disposição extensiva à codificação de cargo e atividades.

Computando a data de início das situações institucionais de trabalho (nome e natureza da instituição), procedeu-se à sua relação por referência ao período de realização da PósGraduação. Cada envolvimento institucional foi classificado como tendo início antes, durante ou depois do referido período.

O cargo viabilizou a caracterização da diversidade hierárquica das situações ocupacionais codificadas anteriormente. Muitas vezes, esta informação vinha especificada no item de atividades. Procedendo à crítica de preenchimento, esses dados foram devidamente corrigidos.

No caso da categoria de docentes e pesquisadores, foram incluídos os visitantes, substitutos ou colaboradores. Na categoria dos técnicos-assistenciais, foram incluídos profissionais universitários que exerciam suas funções em serviços assistenciais, tais como médicos, educadores, assistentes sociais, psicólogos, enfermeiros, arquitetos, entre outros, tendo sido incluídos os epidemiologistas e sanitaristas. Dando conta dos eixos constitutivos da área, foram consideradas as funções administrativas, incluindo os postos de direçâo e gerenciamento, no âmbito da administração pública. A propósito, valorizando o posto hierárquico em detrimento da inserção formal, foram incluídos, na subcategoria de responsáveis por serviços, profissionais que exerciam funções de gerenciamento nas áreas assistenciais, na coordenação de projetos ou de cursos, seminários e estágios. Da mesma forma, em outra subcategoria, foram incluídos coordenadores regionais, diretores de departamento de ensino ou de serviços assistenciais e de pesquisa, assim como diretores técnicos, científicos, de resursos humanos, de planejamento etc. Por fim, destacamos os cargos executivos de Secretário de Saúde, PróReitor, Diretor e Vice-diretor de Faculdade, Presidente de Associações Nacionais etc., 
seguidos de Assistentes de Direção nestas esferas de atuação.

As atividades foram codificadas, tendo por referência o ensino, a assistência, a pesquisa e a administração, sendo registradas até três atividades por ocupação, obedecendo à ordem referida pelos entrevistados. Além da confusão das atividades com o cargo, ou o registro genérico a ele associado, notamos o fato de que o instrumento de coleta não propiciou o registro sistemático de informações referentes aos eixos acima apontados. Diante das restrições do instrumento de investigação, apresentamos os dados globais sem especificar as instituições nas quais havia sido realizada a Pós-Graduação, procurando mais do que os resultados quantitativos, indícios sobre o perfil das atividades dos egressos da área de Saúde Coletiva.

A coleta de informações sobre "outras atividades" exercidas pelos egressos visou apreender as esferas de atuação relacionadas com a qualificação profissional, paralelas aos empregos formalmente referidos. Estes dados foram categorizados da mesma forma que o item anterior. Quanto ao preenchimento, observamos, com certa freqüência, que as informações eram explicativas das situações empregatícias arroladas no quesito anterior. Estes dados foram criticados e devidamente revisados. Para efeito de tabulação das informações, consideramos até duas situações de envolvimento profissional, dando conta da maioria dos casos que tinham mais de uma atividade.

A relevância da Pós-Graduação foi considerada por referência à alteração de atividades (empregos, cargos e funções), mudança de salários e outras possibilidades referidas pelos egressos. A quantificação destes quesitos, assim como qualquer outra medida de impacto da Pós-Graduação em Saúde Coletiva, devem ser consideradas com reservas. Dada a complexidade da questão, a análise de dados foi realizada tendo em vista, sobretudo, a obtenção de pistas para o aprofundamento futuro da investigação do tema.

\section{Resultados}

Ressaltamos que estes resultados diferem daqueles apresentados no relatório prelimi-

Tabela 2

Egressos de Pós-Graduação em Saúde Coletiva que Divulgaram Teses/Dissertações, segundo Instituição, no Período de 1990 a 1994

\begin{tabular}{|c|c|c|c|c|c|c|c|c|}
\hline \multirow{3}{*}{ Instituição } & \multicolumn{6}{|c|}{ Divulgação } & \multirow{2}{*}{\multicolumn{2}{|c|}{ Total }} \\
\hline & \multicolumn{2}{|c|}{ Sim } & \multicolumn{2}{|c|}{ Não } & \multicolumn{2}{|c|}{ S/ Informação } & & \\
\hline & № & $\%$ & $\mathrm{~N}^{\circ}$ & $\%$ & № & $\%$ & № & $\%$ \\
\hline ENSP & 75 & 79,8 & 19 & 20,2 & 0 & 0,0 & 94 & 100,0 \\
\hline FMRPNSP & 14 & 63,6 & 5 & 22,7 & 3 & 13,6 & 22 & 100,0 \\
\hline FSPNSP & 33 & 63,5 & 15 & 28,8 & 4 & 7,7 & 52 & 100,0 \\
\hline MPNSP & 15 & 68,2 & 7 & 31,8 & 0 & 0,0 & 22 & 100,0 \\
\hline UEL & 1 & 50,0 & 1 & 50,0 & 0 & 0,0 & 2 & 100,0 \\
\hline UERJ & 24 & 80,0 & 6 & 20,0 & 0 & 0,0 & 30 & 100,0 \\
\hline UFBa & 13 & 65,0 & 3 & 15,0 & 4 & 20,0 & 20 & 100,0 \\
\hline UFPel & 5 & 100,0 & 0 & 0,0 & 0 & 0,0 & 5 & 100,0 \\
\hline UNICAMP & 2 & 100,0 & 0 & 0,0 & 0 & 0,0 & 2 & 100,0 \\
\hline UNIFESP/EPM & 7 & 87,5 & 1 & 12,5 & 0 & 0,0 & 8 & 100,0 \\
\hline Total & 189 & 73,5 & 57 & 22,2 & 11 & 4,3 & 257 & 100,0 \\
\hline
\end{tabular}


Tabela 3

Egressos de Pós-Graduação em Saúde Coletiva que Divulgaram Teses/Dissertações, segundo Veículo e Instituição, no Período de 1990 a 1994

\begin{tabular}{|c|c|c|c|c|c|c|c|c|c|c|c|c|c|c|}
\hline \multirow{3}{*}{ Instituiçāo } & \multirow{2}{*}{\multicolumn{2}{|c|}{ Egressos }} & \multicolumn{12}{|c|}{ Veículos } \\
\hline & & & \multicolumn{2}{|c|}{ Livro } & \multicolumn{2}{|c|}{ Cap. Livro } & \multicolumn{2}{|c|}{ Rev. Nac. } & \multicolumn{2}{|c|}{ Rev. Est. } & \multicolumn{2}{|c|}{ Congr. Nac. } & \multicolumn{2}{|c|}{ Congr. Estr. } \\
\hline & № & $\%$ & № & $\%$ & № & $\%$ & № & $\%$ & № & $\%$ & № & $\%$ & № & $\%$ \\
\hline ENSP & 94 & 100,0 & 13 & 13,8 & 11 & 11,7 & 31 & 33,0 & 8 & 8,5 & 54 & 57,4 & 17 & 18,1 \\
\hline FMRP/USP & 22 & 100,0 & 0 & 0,0 & 0 & 0,0 & 7 & 31,8 & 1 & 4,5 & 10 & 45,5 & 1 & 4,5 \\
\hline FSP/USP & 52 & 100,0 & 5 & 9,6 & 1 & 1,9 & 15 & 28,8 & 3 & 5,8 & 21 & 40,4 & 6 & 11,5 \\
\hline MP/USP & 22 & 100,0 & 5 & 22,7 & 5 & 22,7 & 9 & 40,9 & 2 & 9,1 & 9 & 40,9 & 6 & 27,3 \\
\hline UEL & 2 & 100,0 & 0 & 0,0 & 0 & 0,0 & 0 & 0,0 & 0 & 0,0 & 1 & 50,0 & 0 & 0,0 \\
\hline UERS & 30 & 100,0 & 2 & 6,7 & 4 & 13,3 & 16 & 53,3 & 2 & 6,7 & 14 & 46,7 & 6 & 20,0 \\
\hline UFBa & 20 & 100,0 & 1 & 5,0 & 0 & 0,0 & 6 & 30,0 & 0 & 0,0 & 12 & 60,0 & 4 & 20,0 \\
\hline UFPel & 5 & 100,0 & 0 & 0,0 & 0 & 0,0 & 4 & 80,0 & 2 & 40,0 & 4 & 80,0 & 1 & 20,0 \\
\hline UNICAMP & 2 & 100,0 & 0 & 0,0 & 0 & 0,0 & 1 & 50,0 & 2 & 100,0 & 1 & 50,0 & 0 & 0,0 \\
\hline UNIFESP/EPM & 8 & 100,0 & 1 & 12,5 & 0 & 0,0 & 2 & 25,0 & 1 & 12,5 & 5 & 62,5 & 3 & 37,5 \\
\hline Total & 257 & 100,0 & 27 & 10,5 & 21 & 8,2 & 91 & 35,4 & 21 & 8,2 & 131 & 51,0 & 44 & 17,1 \\
\hline
\end{tabular}

nar (Minayo \& Costa, 1996), na medida em que foram revisados e incluíram dados não explorados anteriormente.

Obedecendo à ordem seqüencial dos itens da ficha $C$, iniciamos pela apresentação dos resultados relativos à divulgação das dissertações/teses, observando que, a despeito dos diferenciais de tempo de defesa de dissertação/tese, foi elevada a proporção de sua divulgação. De acordo com a Tabela 2, 73,5\% das dissertações/teses resultaram em alguma forma de comunicação. Do conjunto amostral (Tabela 3), ressaltamos a proporção significativa de egressos que apresentaram trabalhos em Congressos Nacionais $(51,0 \%)$, seguida de publicações em Revistas Nacionais $(35,4 \%)$.

Viacava, no capítulo sobre difusão da produção científica do relatório preliminar (Minayo \& Costa, 1996), trabalhando com dados da EXECAPES, encontrou proporções semelhantes de divulgação científica em revistas nacionais e internacio- nais. O mesmo não se observou com relação à divulgação de trabalhos em Congressos Nacionais e Internacionais, assim como em relação à publicação de Livros, cujas proporções foram menores do que os dados por nós observados. Ressalve-se, a propósito, as diferenças com relação às fontes e categorias de classificação adotadas, de um lado, e o fato de que nosso levantamento trabalhou com um segmento específico e num momento singular da construção de conhecimento.

Os dados classificados pelo ano de titulação (Gráfico 1) apontaram um aumento 
sistemático de todos os canais considerados, sendo que as diferenças encontradas entre os anos de 1990 e 1993/94 foram estatisticamente significantes $(\mathrm{p}<0,05)$, segundo o teste de Friedman. Esta elevação é consistente com outros estudos que, partindo de distintas fontes, evidenciaram aumento da produção científica (Minayo \& Costa, 1996).

Estes resultados descartam as suspeitas iniciais de que a proporção de divulgação seria maior entre aqueles que teriam defendido a dissertação/tese há mais tempo, ressaltando, outrossim, os reflexos das diretrizes políticas adotadas pelos órgãos de direção nacional, que passaram a privilegiar a avaliação da produtividade, pelos veículos supracitados.

Dentre os diferentes veículos considerados, a publicação em revista estrangeira e a participação em congressos internacionais foram os que apresentaram maior crescimento relativo; a publicação em revistas nacionais e a participação em congressos nacionais também cresceram, porém, em menores proporções. Já a publicação de livros e capítulos de livros aumentou até 1993, decres- cendo posteriormente para níveis similares aos de 1992.

Constatamos proporções semelhantes de divulgação das dissertações/teses entre aqueles que exerciam suas funções em universidades e fundações/institutos (77,0\%), assim como em serviços $(70,0 \%)$, não havendo distinção digna de nota quando da consideração dos canais de divulgação.

No caso da alternativa "outros", os dados incluíram referências a seminários, palestras, confecção de apostilas, relatórios, boletins etc. Neste sentido, se a área tem produtos específicos, e eles devem ser valorizados na consideração dos critérios de avaliação, ela não é imune aos estímulos adotados pelas agências financiadoras, respondendo com agilidade aos mesmos. A propósito, a referência à adesão a estas políticas não só condiz com o perfil de divulgação das dissertações/teses como aponta para a equiparação do desempenho da área de Saúde Coletiva às demais áreas de Pós-Graduação.

Com relação à absorção dos egressos no mercado de trabalho, observamos (Tabela 4) que eles tinham em média 1,16 empregos,

Tabela 4

Número e Média de Empregos de Egressos de Pós-Graduação em Saúde Coletiva, segundo Instituição, no Período de 1990 a 1994

\begin{tabular}{|c|c|c|c|c|c|c|c|c|c|c|c|}
\hline \multirow{3}{*}{ Instituição } & \multicolumn{11}{|c|}{ Empregos } \\
\hline & \multicolumn{2}{|c|}{0} & \multicolumn{2}{|c|}{1} & \multicolumn{2}{|c|}{2} & \multicolumn{2}{|c|}{3} & \multicolumn{2}{|c|}{ Total } & \multirow{2}{*}{ Média } \\
\hline & № & $\%$ & № & $\%$ & № & $\%$ & № & $\%$ & № & $\%$ & \\
\hline ENSP & 5 & 5,3 & 68 & 72,3 & 19 & 20,2 & 2 & 2,1 & 94 & 100,0 & 1,19 \\
\hline FMRP/USP & 1 & 4,5 & 12 & 54,5 & 8 & 36,4 & 1 & 4,5 & 22 & 100,0 & 1,41 \\
\hline FSP/USP & 8 & 15,4 & 43 & 82,7 & 1 & 1,9 & 0 & 0,0 & 52 & 100,0 & 0,87 \\
\hline MP/USP & 1 & 4,5 & 15 & 68,2 & 3 & 13,6 & 3 & 13,6 & 22 & 100,0 & 1,36 \\
\hline UEL & 0 & 0,0 & 2 & 100,0 & 0 & 0,0 & 0 & 0,0 & 2 & 100,0 & 1,00 \\
\hline UERJ & 1 & 3,3 & 24 & 80,0 & 5 & 16,7 & 0 & 0,0 & 30 & 100,0 & 1,13 \\
\hline UFBa & 4 & 20,0 & 8 & 40,0 & 7 & 35,0 & 1 & 5,0 & 20 & 100,0 & 1,25 \\
\hline UFPel & 0 & 0,0 & 4 & 80,0 & 1 & 20,0 & 0 & 0,0 & 5 & 100,0 & 1,20 \\
\hline UNICAMP & 0 & 0,0 & 2 & 100,0 & 0 & 0,0 & 0 & 0,0 & 2 & 100,0 & 1,00 \\
\hline UNIFESP/EPM & 0 & 0,0 & 5 & 62,5 & 3 & 37,5 & 0 & 0,0 & 8 & 100,0 & 1,38 \\
\hline Total & 20 & 7,8 & 183 & 71,2 & 47 & 18,3 & 7 & 2,7 & 257 & 100,0 & 1,16 \\
\hline
\end{tabular}

$0=$ Não trabalha ou Sem informação 
sendo que $71,2 \%$ dos egressos referiram 1 emprego; $18,3 \%$ referiram 2 empregos e 2,7\% referiram 3 empregos. Levando em conta os dados por instituição de Pós-Graduação (Tabela 4), somente os egressos da FSP-USP apresentaram média inferior a um emprego $(0,87)$, ressaltando-se a elevada proporção de casos sem informação no levantamento desta instituição, que incluem, na sua maioria, as situações de alunos que não caracterizavam uma situação formal de inserção. Se as contingências locais parecem indicar formas peculiares de envolvimento profissional, estes diferenciais também nos conduzem a apontar a possibilidade de existência de problemas relacionados com os procedimentos operacionais da investigação nas diferentes instituições.

Quanto ao tipo e à natureza das instituições onde os egressos exerciam suas funções profissionais, destacamos (Gráfico 2) o registro de $32,4 \%$ do exercício de atividades ocupacionais em universidades públicas; $29,2 \%$ em serviços públicos de saúde; e $21,7 \%$ em institutos e fundações, igualmente públicos.
Estas concentrações se repetiram, em certo sentido, quando observamos os dados por curso de Pós-Graduação, ressalvando a diversidade histórica, a vocação e o porte dos mesmos. No caso da ENSP, por exemplo, existe a inserção formal dos profissionais na qualidade de pesquisadores, embora as atividades sejam semelhantes às de um docente. Na FSP-USP e na UERJ, assim como na UNIFESP, observamos maior proporção de docentes. Na Medicina Preventiva-USP e Medicina Preventiva-RP, observamos maior proporção de egressos envolvidos com serviços de saúde. Na UFBa, estas funções se apresentaram com proporções semelhantes, resguardada a elevada proporção de "sem informação" (somente inferior à da FSP-USP).

Vale dizer que, do conjunto das situações ocupacionais, $32 \%$ dos egressos já estavam envolvidos nas referidas instituições antes do início da Pós-Graduação; 20,5\% foram incorporados durante o período de realização da Pós-Graduação e 47,5\%, depois de titulados, particularmente nas universidades.

Estratificando estes dados por referência ao tipo de instituições, ou seja, consideran-

Gráfico 2- Natureza da Instituição das Situações Ocupacionais. Egressos de Pós-Graduação em Saúde Coletiva, 1990 a 1994.

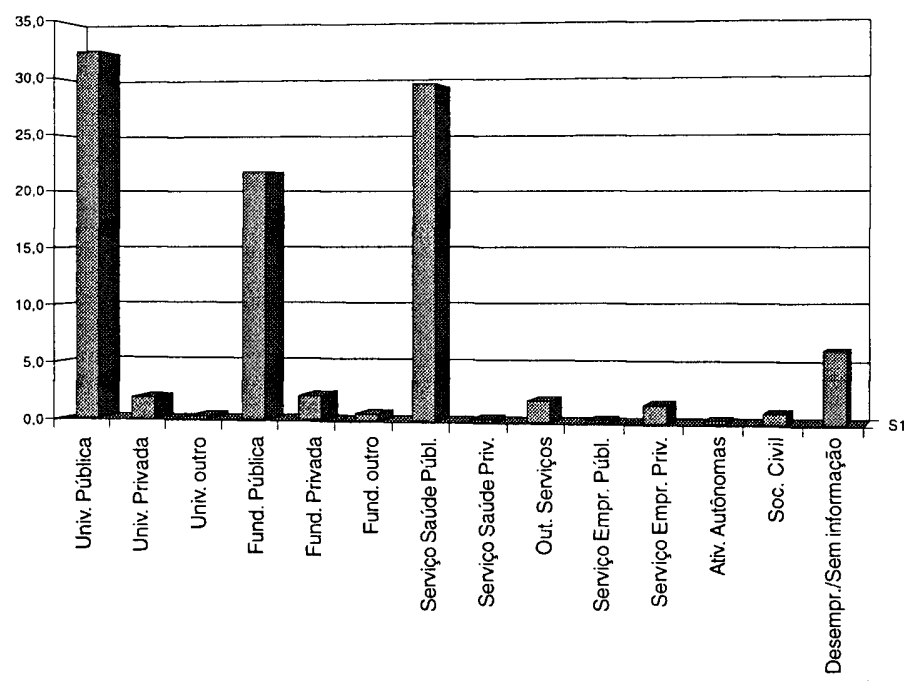


do de um lado os egressos que exerciam suas funções em universidades e fundações/institutos e, de outro, nos serviços, chamou a atenção a semelhança de proporções daqueles que haviam ingressado no mercado de trabalho antes do início da Pós-Graduação: $32,0 \%$ e $35,0 \%$, respectivamente. Quanto aos demais, observamos proporção maior dos que ingressaram no mercado de trabalho durante a Pós-Graduação, entre os egressos que exerciam suas funções nos serviços assistenciais $(29,0 \%)$ e depois de finalizada a Pós-Graduação, maior concentração foi constatada entre aqueles que exerciam suas funções em universidades e institutos/fundações $(55,0 \%)$.

De forma condizente com o quadro das instituições acima descrito, observamos, por referência aos cargos exercidos (como mostra o Gráfico 3), uma concentração de docentes $(31,1 \%)$ e de profissionais com funções técnico-assistenciais $(26,4 \%)$, seguidos de profissionais com funções administrativas (16,3\%) e de pesquisa (15,7\%). A respeito das funções administrativas, sua presença condiz com os dados apresentados por Nunes no capítu- lo sobre estrutura curricular, que refere o despontar desta subárea no desenvolvimento da Saúde Coletiva (Minayo \& Costa, 1996).

Na ENSP destacamos a presença de pesquisadores ao lado dos docentes. Na Medicina Preventiva de Ribeirão Preto e na UNIFESP foram encontrados valores expressivos de profissionais técnico-assistenciais vinculados à assistência à Saúde. Na Medicina Preventiva da USP encontrou-se proporção equivalente de pesquisadores e de funcionários técnico-assistenciais, enquanto na UERJ foi constatada equivalência de técnico-assistenciais e de docentes. Na Faculdade de Saúde Pública da USP, por uma questão de porte ou de viés na coleta de informações (só foram acessados 27,8\% do universo de egressos titulados), observamos maiores proporções de docentes (51\%).

Levando em conta o conjunto das 426 atividades das distintas situações de trabalho, observamos que $30 \%$ referiam atividades de pesquisa, seguido de $25 \%$ de atividades de ensino, 21\% de assistência e $9 \%$ de atividades administrativas, ao lado de 10\% "sem informação" que incluíam as situações de

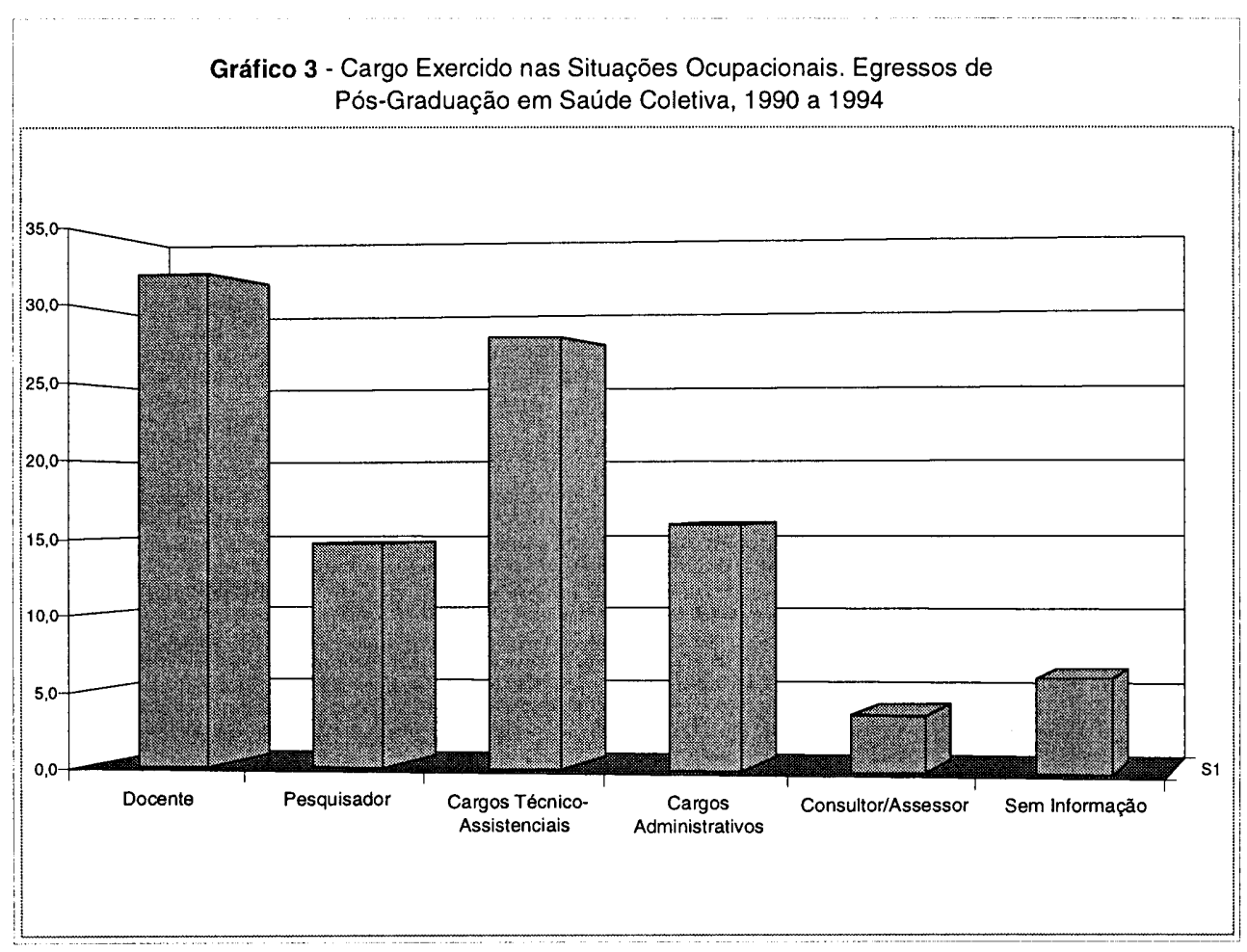


alunos, profissionais afastados e sem informação propriamente dita.

Em que pesem os limites da presente sondagem, o registro das atividades ressaltou o tangenciamento da atividades de docência, pesquisa e assistência, ao lado das político-administrativas, que despontam como relevante espaço constitutivo da área. Este dado foi tanto observado por referência a um mesmo cargo, como pela complementaridade destas atividades no conjunto de situações empregatícias exercidas por um mesmo entrevistado.

Considerando o tipo de instituição das situações de trabalho, observamos que nas universidades e fundações, $15 \%$ exerciam atividades assistenciais, $36 \%$ atuavam como pesquisadores e $4 \%$, como administradores. Por sua vez, reforçando esta combinação de atividades entre aqueles que trabalhavam em serviços assistenciais, 9\% se dedicavam ao ensino, 31\% à pesquisa e $19 \%$ à administração. Detalhar as atividades e apreender a mobilidade entre elas, em distintas situações conjunturais, constituiria um passo importante no sentido de especificar com mais clareza o perfil de inserção dos egressos no mercado de trabalho tendo por referência o processo de especialização e seus reflexos sobre a configuração deste mercado.

Do conjunto de egressos, $42,8 \%$ informaram o exercício de "outras atividades", complementares àquelas através das quais caracterizaram sua inserção no mercado de trabalho, o que nos permite denominá-las de atividades principais por referência às atividades complementares (Gráfico 4). Embora cerca de $15 \%$ não tivesse preenchido este quesito (proporção esta que variou entre as instituições), observamos, quanto ao exercício de outras funções, referência superior a 46,7\% na UERJ, ENSP e UNIFESP; entre as demais, os valores foram da ordem de 30,0 a $36,0 \%$.

Quanto à natureza e ao cargo destas funções complementares, o preenchimento foi
Gráfico 4 - Outras Atividades. Egressos de Pós-Graduação em Saúde Coletiva. 1990-1994

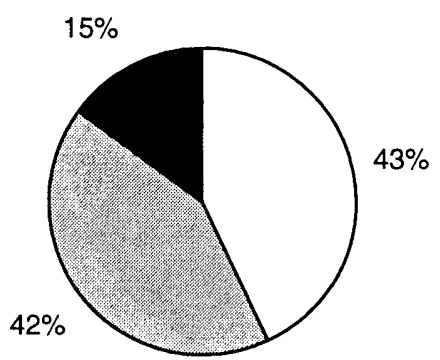

prejudicado em certo sentido, na medida em que se tratava de uma questão aberta. Vale lembrar que nestes segmentos foram incluídas as situações de alunos de Pós-Graduação que não tinham nenhuma inserção formal de trabalho (registrado no quesito anterior) e que foram enquadrados na categoria "sem informação".

No tocante ao tipo e natureza das instituições em que executavam as atividades "complementares" (Gráfico 5), a par do nível de "sem informação", que chegou a 37,3\%, chamou a atenção, na comparação com as atividades principais, a redução de atividades em universidades, instituições e fundações, bem como em serviços públicos. Por outro lado, observamos um grau significativo de participação em entidades da sociedade civil, cuja cifra chegou a $14,5 \%$, enquanto nas ocupações "principais" a presença de emprego nestas instituições foi de $0,9 \%$. Outrossim, ressaltamos o aumento da proporção relativa em instituições privadas, particularmente no âmbito das universidades, quando as proporções passaram quase a se equivaler.

Particularmente no tocante ao cargo (Gráfico 6), a proporção de "sem informação" chegou a $27,2 \%$, sendo que $22,7 \%$ eram alunos. Das informações restantes, chama a atenção a presença de $21,8 \%$ de referências à realização de consultoria dentre as atividades complementares, de 19,1\% à 
Gráfico 5 - Natureza da Instituição das "Outras" Situações Ocupacionais. Egressos de Pós-Graduação em Saúde Coletiva, 1990 a 1994.

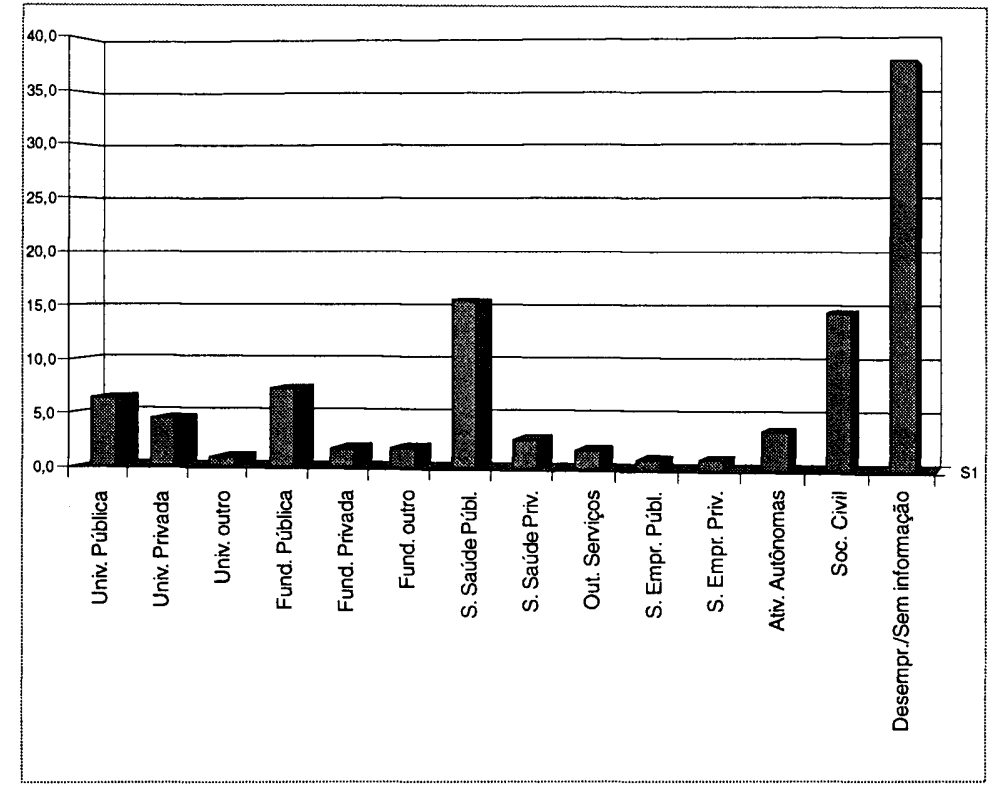

Gráfico 6 - Cargo Exercido nas "Outras" Situações Ocupacionais. Egressos de Pós-Graduação em Saúde Coletiva, 1990 a 1994.

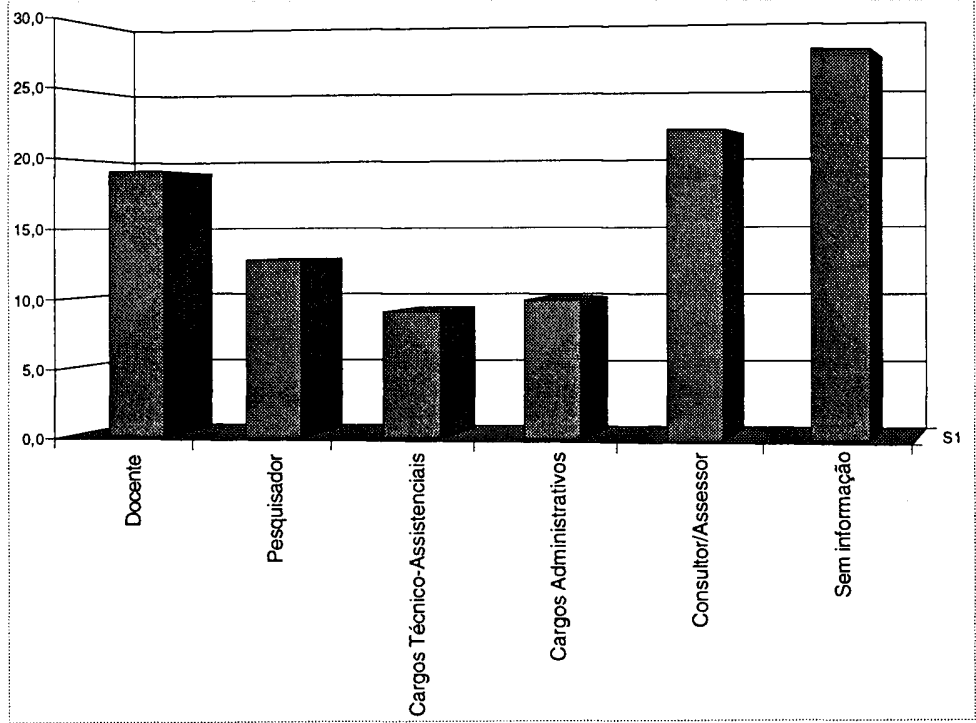


Gráfico 7 A - Alteração de Atividade

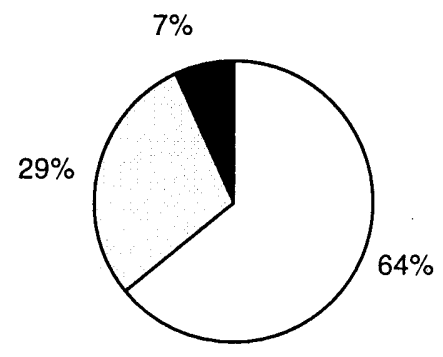

Gráfico 7 B - Aumento de Remuneração $\square \operatorname{sim}$ $\square$ não

s / inf.
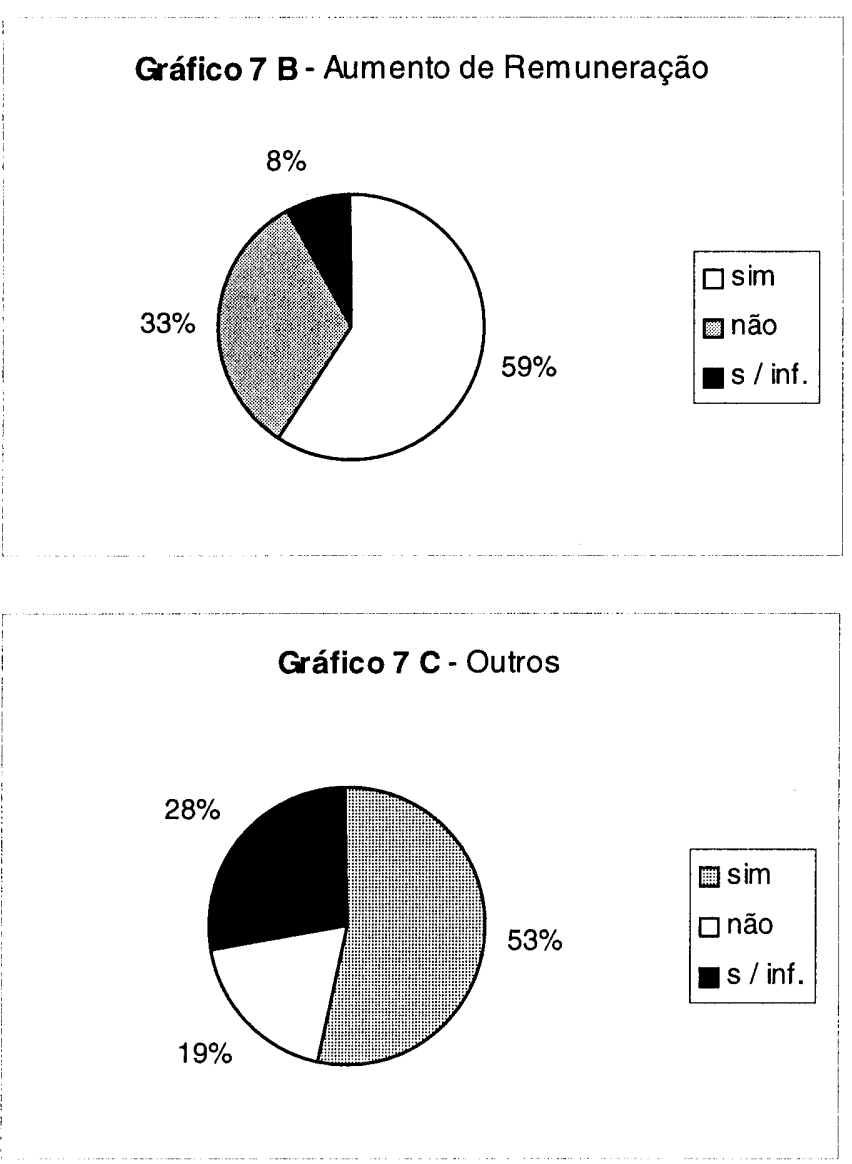

docência e 9,0\% às funções administrativas.

Em relação às atividades, os resultados vieram reforçar a questão da complementaridade, levando em conta o conjunto das situações de trabalho, tanto as principais como as complementares, por egresso. Dentre os múltiplos casos a serem arrolados, este seria o caso do docente que dá consultoria numa empresa privada ou dirige um setor de pesqui-

sa numa ONG; ou, do técnico-assistencial que ministra aula numa universidade ou realiza pesquisa numa instituição civil; ou ainda o caso de um docente ou pesquisador que presta assistência na rede assistencial ou numa ONG etc. Não só a assistência, docência, pesquisa e o exercício de funções administrativas tangenciam um mesmo cargo, como se complementam numa gama de combinações de situações de trabalho.

Por fim, os resultados sobre a relevância da Pós-Graduação (Gráfico 7) registraram $63,8 \%$ de egressos que afirmaram mudanças de atividades (emprego, funções etc.) após a conclusão da Pós-Graduação; 59,1\% referiram mudança de salário, e 53,1\% referiram outras alternativas. Em que pesem estas elevadas proporções, não se pode deixar de destacar as repostas negativas a estes quesitos: $29,2 \%$ não referiram alteração de atividades, e 33,1\% afirmaram a inexistência de alteração de salário.

Da perspectiva das instituições de Pós-Graduação, observamos que, na FSPUSP, na UERJ e particularmente na ENSP, foram mais elevadas as proporções de entrevistados que referiram alteração de atividades e aumento de salários. No caso da Medicina Preventiva da USP e de Ribeirão Preto-USP, em particular, as proporções dos que referiram alteração de atividades e aumento de salários se apresentaram mais equilibradas. Já na UFBa, $45 \%$ referiram não haver alteração de atividades, enquanto na UNIFESP, $87 \%$ referiram não ter havido aumento de salário. Sem pretender explicar as diferenças observadas, o que transcenderia o âmbito do presente trabalho, a interpretação destes resultados não poderia deixar de apontar para a relevância do fato de ser a titulação para a clientela de pósgraduandos da área requisito de carreira acadêmica ou de pesquisador, em detrimento daqueles que estariam fora dela. 
Dentre os que referiram outros parâmetros com relação à relevância da Pós-Graduação em suas vidas profissionais $(53,1 \%)$ - categoria "outro" -, constatamos tanto a presença de informantes que assinalaram "sim" para este quesito, mas não especificaram a alternativa, assim como dos que procederam a esta especificação, mesmo tendo deixado em branco ou respondido negativamente ao referido quesito. Relativizando o não-preenchimento deste quesito, ressalvamos que na verdade somente $8,6 \%$ responderam negativamente aos três quesitos.

Entre os que responderam a esta alternativa e à(s) anterior(es), ressaltamos a busca de aquisição de base para a formação profissional e o aprimoramento e capacitação para o desempenho profissional, ao lado de metas específicas como o "incremento de conhecimento na área de informática" ou de "prevenção da AIDS junto às ONGs" etc.

Paralelamente, os egressos mencionaram que a Pós-Graduação teria propiciado o "contato com a pesquisa institucional"; o "acesso ao financiamento de pesquisa e às bolsas da CAPES e CNPq, no país e no exterior"; o "contato com outras instituições" e a realização de consultoria/assessoria à pesquisa, bem como a "abertura de oportunidade de realização de trabalho no país e no exterior".

Ao lado da valorização da participação em comissões, grupos de estudo e de pesquisa ou, simplesmente, do caráter gratificante de um convívio enriquecedor com coordenadores, vários entrevistados/informantes expressaram a abertura de campos de trabalho, propiciada pela Pós-Graduação ou o aumento de atividades de docência e pesquisa, paralelamente às mudanças de cargos e empregos. Em um dos casos, o egresso registrou o reconhecimento de que a Pós-Graduação contribuíra para o exercício do debate e a elaboração de relatorias no âmbito das suas atividades parlamentares.

Interessante notar, por sua vez, a expressiva freqüência de menção à importância da
Pós-Graduação entre egressos que não acusaram alteração nem de atividades nem de remuneração (quesitos anteriores). Seguindo pelos mesmos eixos referidos anteriormente, ressaltaram, ao lado do desenvolvimento de pesquisa e da oportunidade de participação em seminários, congressos e de divulgação do trabalho realizado, o aumento de conhecimento e aprimoramento do desempenho profissional e das atividades técnico-científicas. Alguns informantes destacaram o reconhecimento do trabalho desenvolvido, assim como a ampliação do campo de interlocução acadêmica propiciados pela realização da Pós-Graduação.

Particularmente em relação aos egressos inseridos no âmbito dos serviços, constatamos a referência ao peso do título no gerenciamento e planejamento de serviços em situação de conflitos técnico-políticos, ao lado da valorização da Pós-Graduação como canal que afeta a qualidade dos serviços, a despeito das dificuldades de liberação dos funcionários para sua realização. Outros ainda levantaram a valorização do processo, mais do que da titulação propriamente dita, sendo digno de nota a referência ao "tesão para continuar" (os estudos) propiciado pela oportunidade de participação na Pós-Graduação.

A propósito destas considerações, ressaltase, de um lado, a temeridade de estabelecer conexões diretas entre a Pós-Graduação e as medidas de sucesso, reduzindo a multiplicidade de determinações envolvidas num encadeamento linear, a-histórico e, de outro, chamar atenção para a relevância de sua consideração na busca de balizamentos, tendo em vista a necessidade de compatibilizar a qualidade do ensino à modernização do conhecimento e das técnicas profissionais correlatas.

\section{Conclusões}

O acesso à metade do universo de egressos de Pós-Graduação em Saúde Coletiva que 
defenderam a dissertação/tese no período de 1990 a 1994 viabilizou, sem dúvida, um aporte significativo de informaçôes a respeito das questões que esta sondagem perseguiu. $O$ acesso diferenciado por instituições, porém, não só relativiza o alcance dos resultados levantados, como aponta para a necessidade de alcançar uma amostra representativa, para efeito de realização de um diagnóstico mais efetivo. Conforme proposição do projeto original, este diagnóstico reforça a necessidade de envolver a participação das coordenações das respectivas Pós-Graduações, com vistas à instalação de um sistema contínuo de avaliação, em seus respectivos espaços de atuação, capaz de responder à dinâmica de constituição e desenvolvimento dá área.

Coincidindo com a aplicação das disposições políticas adotadas desde a institucionalização da Pós-Graduação no país de estímulo à formação de docentes e pesquisadores, apoiado pelas agências financiadoras, o levantamento constatou a concentração de egressos em instituições públicas; o exercício profissional em instituições privadas, de caráter residual, apresentou um aumento proporcional no caso das atividades complementares.

Ao lado do envolvimento profissional como docentes e pesquisadores, o levantamento acusou a presença significativa de egressos incorporados em serviços assistenciais, seguida de egressos que exerciam funções administrativas. Tal perfil dá conta da abrangência de constituição da área de Saúde Coletiva, ressalvando-se a diversidade de cursos que a integram. A consideração das atividades chamou a atenção pela complementaridade do ensino, pesquisa, assistência e administração, seja entre os egressos que exerciam suas funções nas universidades ou institutos/fundações, seja nos serviços assistenciais. Estes dados apontam simultaneamente para a amplitude do potencial de atuação da própria Pós-Graduação em Saúde Coletiva e do desenvolvimento de suas áreas de concentração, e evidenciam os impasses e desafios que se impõem, em meio à dinâmica das políticas assislencias e de Ciência \& Tecnologia que se estruturam paralelamente às transformações que vêm ocorrendo nas organizações produtivas e no mercado de trabalho.

Por reterência à questão da absorção dos egressos no mercado de trabalho como indicativo da capacidade de qualificação profissional oferecida, chamou a atenção, de um lado, o pequeno número dos que não estavam inseridos no mercado de trabalho e, de outro, que somente um terço, daqueles que referiram inserção no mercado de trabalho, o haviam feito antes do início da Pós-Graduação. Esta proporção foi semelhante tanto entre os egressos que exerciam suas funções em universidades e institutos/fundações, quanto nos serviços assistenciais, sugerindo que a referida qualificação profissional atenderia não só aos requisitos da academia como dos serviços.

De forma consistente, considerando as referências sobre a relevância da Pós-Graduação na vida profissional, a maioria dos egressos apontou para a alteração das atividades (empregos/cargos) e/ou aumento de remuneração. Em que pese o caráter exploratório da sondagem, com vistas à obtenção de pistas para a realização de investigações futuras sobre esta complexa relação, chamou a atenção a explicitação, por parte dos egressos, do papel da Pós-Graduação na qualificação profissional e abertura de oportunidades de trabalho, dentre as quais foi citada a possibilidade de realização de pesquisa e divulgação do trabalho realizado. Tendo em vista a caracterização do perfil da clientela, não poderíamos igualmente deixar de mencionar a possibilidade de contar com as bolsas de estudo que constituiriam alternativas de complementação salarial ou de remuneração para egressos ainda não inseridos no mercado de trabalho, ao lado do simples gosto por cursar a Pós-Graduação.

No tocante à produção de conhecimento, aferida pelo volume de divulgação das dissertações/teses, os resultados apontaram para a aproximação do desempenho da área de 
Saúde Coletiva às demais áreas de Pós-Graduação no país. Aliás, o crescimento do volume de divulgação das dissertações/teses, no período estudado, bem como dos veículos valorizados nas políticas de avaliação ancoradas na produtividade, não confirmou a suspeita de que a difusão seria maior entre os egressos que tivessem defendido suas dissertações/teses há mais tempo. Se estes indicativos de aderência às políticas de avaliação apontam para o desenvolvimento da área, em que pese os limites de sua consideração nesta investigação, também levantam a preocupação com as disposições restritivas da avaliação aos critérios baseados exclusivamente na quantificação da produção de conhecimentos.

\section{Referências bibliográficas}

AMORIM, A. (1992) - Avaliação Institucional da Universidade. São Paulo: Ed. Cortez, São Paulo. MINISTÉRIO DE EDUCAÇÃO E CULTURA (MEC) SES (1988) - Avaliação do Ensino Superior Encontro Internacional. Brasília: MEC-SES.

DURHAM, E.A. (1989) - Institucionalização da Avaliação. Anais do Seminário "A Avaliação do Ensino Superior: Contexto, experiências, desdobramentos e perspectivas". Organizado pelo NUPES, SESU, MEC, OEA. São Paulo, mimeo [Coletânea de textos - NUPES].

GOLDENBERG, P.; STELLA, R.C.R.; GOMES, M.H. de A. \& GOIHMAN, S. (1994) - Projeto Integrado de Avaliação da Pós-Graduação em Saúde Coletiva: Egressos. In: Minayo, M.C. de S. \& Costa, P.S. da (coords.) - Projeto Integrado de Pesquisa - Avaliação da Pós-Graduação Stricto Sensu em Saúde Coletiva no Brasil. ABRASCO, Oficina de Avaliação da Pós-Graduação Stricto Sensu em Saúde Coletiva. Rio de Janeiro, mimeo. MADEIRA, I. R. (1996) - A Pós-Graduação Stricto Sensu,
A considerar a semelhança da proporção de divulgação tanto entre os egressos que exerciam suas funções profissionais em universidades e institutos/fundações, quanto nos serviços assistenciais, estes achados, se não refutam, também não confirmam a hipótese de que a Pós-Graduação atenderia mais ao "Sistema de Ciência \& Tecnologia do que ao Sistema de Serviços de Saúde". Estes resultados não só reforçam a necessidade de discutir os critérios vigentes de avaliação, no âmbito das políticas de Ciência \& Tecnologia, mas de refletir a própria área frente aos novos requisitos de excelência que tendem a se impor, em meio à dinâmica do mercado de trabalho e das transformações sociais em curso.

Nível de Mestrado, Voltada para Pediatras, no Estado do Rio de Janeiro. A Construção de uma Visão Crítica a Partir de seus Egressos. Dissertação de Mestrado, IFF - Fiocruz, Rio de Janeiro, mimeo. MINAYO, M.C. de S. \& COSTA, P.S. da (coords.) (1994) - Projeto Integrado de Pesquisa-Avaliação da Pós-Graduação Stricto Sensu em Saúde Coletiva no Brasil. ABRASCO, Oficina de Avaliação da Pós-Graduação Stricto Sensu em Saúde Coletiva. Rio de Janeiro, mimeo.

MINAYO, M.C. de S. \& COSTA, P.S. da (coords.) (1996) - Avaliação da Pós-Graduação Stricto Sensu em Saúde Coletiva. Relatório preliminar. Rio de Janeiro, mimeo.

SCHWARTZMAN, S. (1989) - O Contexto Institucional e Político da Avaliação do Ensino Superior. Anais do Seminário "A Avaliação do Ensino Superior: Contexto, Experiências, Desdobramentos e Perspectivas". Organizado pelo NUPES, SESU, MEC, OEA. São Paulo, mimeo [Coletânea de Textos - NUPES].

Agradecimentos: Agradecemos a colaboração de Regina C. R. Stella, Mara Helena de Andrea Gomes e a Samuel Goihman, não só pelo suporte ao processamento de dados, realizado no CAIDI (Coordenadoria de Avaliação e Integração de Dados Institucionais da UNIFESP), como pelas críticas e sugestões ao trabalho desenvolvido. 